\title{
STIMULATION OF PROLYL HYDROXYLASE ACTIVITY BY BLEOMYCIN
}

\author{
Ken Takeda*, Setsuko Kawai, Fumio Kato, Tsunao Tetsuka** and Kunio Konno \\ Department of Biochemistry, School of Medicine, Showa University, \\ 1-5-8, Hatanodai, Shinagawa-ku, Tokyo, Japan
}

(Received for publication June 26, 1978)

\begin{abstract}
The activity of purified prolyl hydroxylase (proline, 2-oxoglutarate dioxygenase, EC 1. 14. 11. 2) was enhanced $3 \sim 8$-fold at a low concentration of ferrous ion $\left(1 \times 10^{-5} \mathrm{M}\right)$ by addition of bleomycin, a glycopeptide antibiotic with antineoplastic activity and a side effect of producing pulmonary fibrosis. The maximum stimulation was attained at a concentration of $15 \mu \mathrm{g} / \mathrm{ml}$ bleomycin (about $1 \times 10^{-5} \mathrm{M}$ ), which was approximately equimolar with the ferrous ion, one of the cofactors of this enzyme. Addition of bleomycin to the assay mixture resulted in a change of the optimal concentration of ferrous ion from $2 \times 10^{-3} \mathrm{M}$ to $1 \times 10^{-5} \mathrm{M}$. Changing the order of addition of ferrous ion, enzyme and bleomycin in assay medium before incubation at $37^{\circ} \mathrm{C}$, the stimulatory activity was varied. Bleomycin $\mathrm{A}_{2}-\mathrm{Cu}^{++}\left(\mathrm{Cu}^{++}\right.$-chelated bleomycin), which scarcely complexed with $\mathrm{Fe}^{++}$, had no enhancing effects on the enzymatic activity. We discuss the possible reasons as to why the activity of prolyl hydroxylase was enhanced by addition of bleomycin in the assay mixture.
\end{abstract}

Bleomycin, an antitumor antibiotic isolated from Streptomyces verticillus by UMEZAWA et al., ${ }^{1)}$ has been found to be a very useful drug against a number of human cancers, particularly human squamous cell carcinoma. ${ }^{2,3)}$ With increasing use, however, it has become apparent that diffuse pulmonary fibrosis is a severe and puzzling possible complication of bleomycin therapy. ${ }^{4,5}$ ) The pathologic end stage of the toxic reaction, pulmonary fibrosis, has been described in both humans ${ }^{5,6}$ ) and animals, ${ }^{7}$ ) but few studies have been reported on the mechanism of fibrosis by bleomycin. TETSUKA et al. have reported that the drug enhanced collagen synthesis in tissue, ${ }^{8)}$ ICHIHASHI et al. have demonstrated the reduction of cutaneous collagenase activity after administration of the antibiotic, ${ }^{9)}$ and OTSUKA et al. have described the stimulation of the synthesis of acidic glycosaminoglycans in cultured fibroblasts. ${ }^{10)}$

In view of this, the present study was undertaken to attempt an analysis of bleomycin action. In this communication we report the effect of bleomycin on the purified prolyl hydroxylase (proline, 2oxoglutarate dioxygenase, EC 1. 14. 11. 2.), which catalyzes the hydroxylation of peptidyl proline, one of the rate limiting steps in collagen biosynthesis.

\section{Materials and Methods}

Bleomycins were supplied by Nippon Kayaku Co. Ltd., Tokyo. [4- $\left.{ }^{3} \mathrm{H}\right]$ L-Proline (21 Ci/mmol) was a product of Schwarz Bio Research, Inc. Poly(L-proline) and superoxide dismutase were purchased from Sigma Chemical Company.

Enzyme assay

Prolyl hydroxylase activity was assayed according to the method of HuTTON et al. ${ }^{11}$ ) Each assay mixture had a volume of $1 \mathrm{ml}$ and contained the followings: Tris- $\mathrm{HCl}$ buffer (pH 7.5) 200 $\mu \mathrm{mol}$;

* To whom reprint requests should be addressed.

** Present address: Department of Biochemistry, Jichi Medical School, Tochigi-ken, Japan 
sodium ascorbate $2 \mu \mathrm{mol} ; \mathrm{FeSO}_{4} 0.01 \mu \mathrm{mol} ; \alpha$-ketoglutarate $0.4 \mu \mathrm{mol}$; catalase $200 \mu \mathrm{g}$; peptidyl proline $\left[4-{ }^{3} \mathrm{H}\right]$-substrate $(80,000 \mathrm{cpm})$; enzyme preparation $(0.01 \mu \mathrm{g}$ of protein). The substrate was prepared with minced rat embryos according to the same authors, in which $\left[4-{ }^{3} \mathrm{H}\right] \mathrm{L}$-proline had been incorporated as protocollagen-proline in the presence of $\alpha, \alpha^{\prime}$-dipyridyl to prevent hydroxylation. The reaction was carried out for 15 minutes at $37^{\circ} \mathrm{C}$ aerobically with shaking and stopped by adding $0.1 \mathrm{ml}$ of $50 \%$ trichloroacetic acid. Tritiated water formed was collected by vacuum distillation. Radioactivity was determined in a liquid scintillation spectrometer using BRAY's solution. Blanks were less than $30 \mathrm{cpm}$.

\section{Preparation of purified enzyme}

Prolyl hydroxylase was purified by affinity chromatography according to the modified method of TUDERMAN et al. ${ }^{12}$ ). Rat fetuses were minced and homogenized in 3 volumes of buffer solution containing $0.25 \mathrm{M}$ sucrose, $50 \mathrm{~mm}$ Tris- $\mathrm{HCl}(\mathrm{pH} 7.5)$ and $0.02 \mathrm{mM} \mathrm{KCl}$ with a Vir Tis " 45 " homogenizer at maximum speed for 45 seconds and homogenized again in a motor-driven Teflon pestle-glass homogenizer (5 strokes). The $105,000 \times g$ supernatant was fractionated with ammonium sulfate $(30 \sim 65 \%$ saturation). The pellet was dissolved in a solution consisting of $0.1 \mathrm{M} \mathrm{NaCl}, 0.1 \mathrm{M}$ glycine and $0.01 \mathrm{M}$ Tris- $\mathrm{HCl}$ buffer $(\mathrm{pH}$ 7.5). An aliquot of the diluted ammonium sulfate fraction, adjusted to a protein concentration of $10 \mathrm{mg} / \mathrm{ml}$ with buffer, was passed through an affinity column containing poly(L-proline), molecular weight about 30,000 , linked to agarose $(\mathrm{BrCN})$, having a bed volume of $5 \mathrm{ml}$. The enzyme was eluted with $0.01 \mathrm{~m}$ sodium acetate buffer $(\mathrm{pH} 4.0)$ containing $0.2 \mathrm{M}$ sodium chloride. The fractions containing most of the enzymatic activity, neutralized with $\mathrm{NaOH}$, were pooled and stored frozen. The specific activity was 2,000 -fold greater than that of the original $105,000 \times g$ supernatant fraction.

\section{Results and Discussion}

As shown in Fig. 1, the requirement for ferrous ion of prolyl hydroxylase was decreased to about $1 / 100 \sim 1 / 200$ by addition of bleomycin $(15 \mu \mathrm{g} / \mathrm{ml})$, a glycopeptide antibiotic, in the assay medium, i.e., the optimal concentration of ferrous ion was changed from $2 \times 10^{-3} \mathrm{M}$ to $1 \times 10^{-5} \mathrm{M}$. At the relatively low concentration of ferrous ion the enzymatic activity was markedly enhanced by addition of bleomycin. At $1 \times 10^{-5} \mathrm{M}$ ferrous ion concentration, the enzymatic activity in the presence of bleomycin was 5 -fold higher than that of control. LINEWEAVER-BURK plots of the data showed that the control and bleomycin-stimulated activities exhibited no difference in the affinity of enzyme for substrate, and that the primary action of bleomycin was to increase V $\max$.

As shown in Fig. 2, the maximum stimulation was attained at $15 \mu \mathrm{g} / \mathrm{ml}$ of bleomycin (about $1 \times$

Fig. 1. Effect of ferrous ion concentration on the purified prolyl hydroxylase in the absence or in the presence of $15 \mu \mathrm{g} / \mathrm{ml}$ bleomycin.

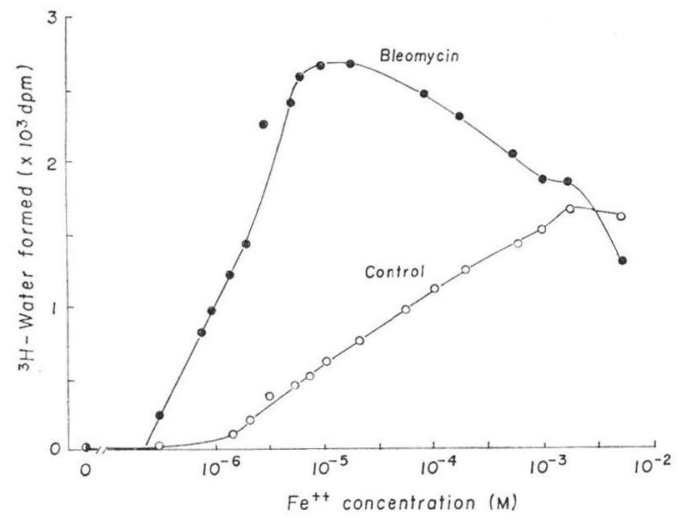

Fig. 2. Effect of bleomycin concentration on the purified prolyl hydroxylase.

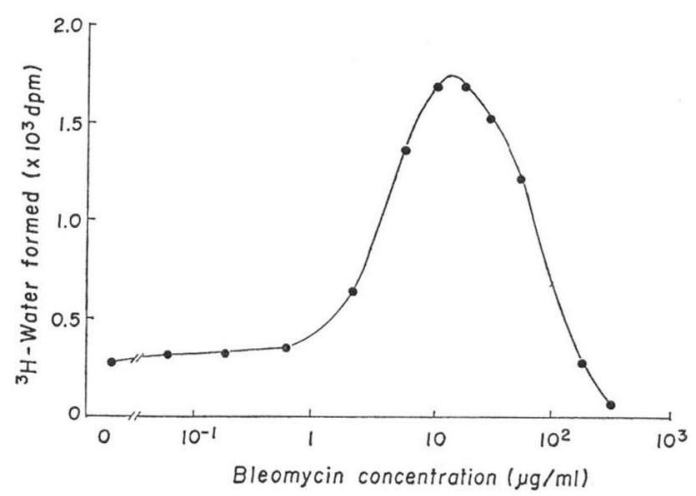


Fig. 3. Effect of addition of bleomycin during the course of incubation on the prolyl hydroxylase activity.

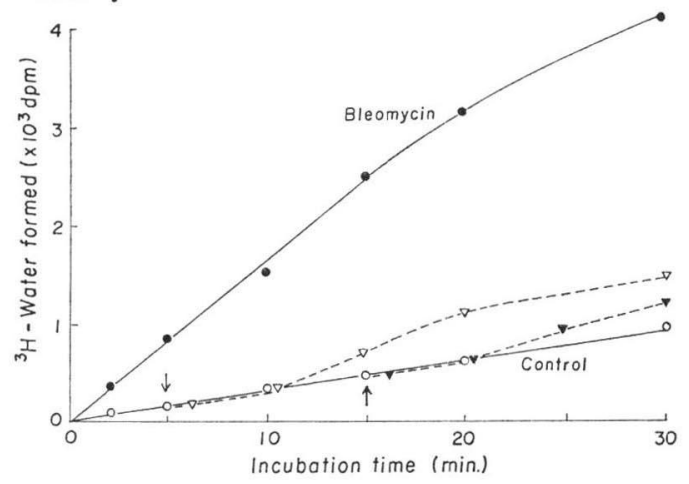

Table 1. Effect of bleomycin $\mathrm{A}_{2}-\mathrm{Cu}^{++}$on purified prolyl hydroxylase.

\begin{tabular}{l|c|c}
\hline \multirow{2}{*}{\multicolumn{1}{c|}{ Addition* }} & \multicolumn{2}{|c}{ Prolyl hydroxylase activity } \\
\cline { 2 - 3 } & dpm & $\%$ of control \\
\hline None & 606 & 100 \\
Bleomycin $\mathrm{A}_{2}$ & 4,832 & 797 \\
Bleomycin $\mathrm{A}_{2}-\mathrm{Cu}^{++}$ & 571 & 94 \\
\hline
\end{tabular}

* The concentration of bleomycins used was $15 \mu \mathrm{g} / \mathrm{ml}$.

$\left.10^{-5}\right)$, which was approximately equimolar with the ferrous ion in the assay medium. The stimu-

latory activity was decreased precipitously at concentrations greater than $15 \mu \mathrm{g} / \mathrm{ml}$ of bleomycin. Higher concentrations of bleomycin were rather inhibitory to the enzymatic activity.

As shown in Fig. 3, there was a lag time in the appearance of stimulatory activity of bleomycin when it was added during the course of incubation, and the enzymatic activity was not so much enhanced during further 15-minute incubation with bleomycin. Changing the order of addition of ferrous ion, enzyme and bleomycin in assay medium before incubation at $37^{\circ} \mathrm{C}$, the stimulatory activity was varied. For example, addition of bleomycin before enzyme caused 2-fold higher stimulation than the reverse. It may be important for bleomycin action that bleomycin interact first with cofactors, perhaps ferrous ion.

Optical spectral studies have revealed that a complex is formed between bleomycin and ferrous ion. ${ }^{13)}$

As shown in Table 1, addition of bleomycin $\mathrm{A}_{2}$ resulted in an enhancement of prolyl hydroxylase activity by about 8-fold, but bleomycin $\mathrm{A}_{2}-\mathrm{Cu}^{++}\left(\mathrm{Cu}^{++}\right.$-chelated bleomycin), a natural product isolated from Streptomyces verticillus had no effects on the enzymatic activity. Cupric ion alone, in amount equimolar with bleomycin $\mathrm{A}_{2}-\mathrm{Cu}^{++}$, did not interfere with the enzymatic activity. These results suggest that the ability of bleomycin to chelate ferrous ion may be important for the modification of the enzymatic activity.

From these observations it seems that bleomycin may interact with ferrous ion and that bleomycinferrous ion may affect the rate of hydroxylation of protocollagen by prolyl hydroxylase. The stimulatory effect of bleomycin on prolyl hydroxylase was not inhibited by addition of superoxide dismutase, suggesting that neither $\mathrm{O}_{2}^{-}$nor $\mathrm{OH}$ radical is the chemical mediator responsible for the stimulating action of bleomycin.

\section{Acknowledgment}

We are grateful to Dr. A. MAtsudA of Nippon Kayaku Co., Ltd. for helpful discussions. This work was supported in part by grants from Ministry of Education, Japan.

\section{References}

1) Umezawa, H.; K. Maeda, T. Takeuchi \& Y. Okami: New antibiotics, bleomycin A and B. J. Antibiotics 19: $200 \sim 209,1966$ 
2) Clinical Screening Group, EORTC.: Study of clinical efficiency of bleomycin in human cancer. Brit. Med. J. 1970-2: $643 \sim 645,1970$

3) Shastri, S.; R. E. Slayton, J. Wolter, C. P. Perlia \& S. G. Taylor, III: Clinical study with bleomycin. Cancer 28: $1142 \sim 1146,1971$

4) Rudders, R. A. \& G. T. Hensley: Bleomycin pulmonary toxicity. Chest 63: 626 628, 1973

5) Bedrossian, C. W. M.; M. A. Luna, B. MacKay \& B. Lightiger: Ultrastructure of pulmonary bleomycin toxicity. Cancer 32: 44 51, 1973

6) Krous, H. F. \& W. B. Hamlin: Pulmonary toxicity due to bleomycin. Arch. Pathol. 95: 407 410, 1973

7) Adamson, I. Y. R. \& D. H. Bowden: The pathogenesis of bleomycin-induced pulmonary fibrosis in mice. Am. J. Pathol. 77: 185 190, 1974

8) Tetsuka, T.; S. Kawai, K. Konno \& H. Endo: The control mechanism of collagen biosynthesis. (in Japanese) Seikagaku 42: 468, 1970

9) Ichihashi, M.; H. Shinkai, M. Takei \& S. Sano: Analysis of the mechanism of bleomycin-induced cutaneous fibrosis in mice. J. Antibiotics 26: 238 242, 1973

10) Otsuka, K.; S. Murota \& Y. Mori: Stimulatory effect of bleomycin on the synthesis of acidic glycosaminoglycans in cultured fibroblasts derived from rat carrageenin granuloma. Biochim. Biophys. Acta 444: $359 \sim 368,1976$

11) Hutton, J. J. \& S. Udenfriend: Soluble collagen proline hydroxylase and its substrates in several animal tissues. Proc. Nat. Acad. Sci. U.S.A. 56: 198 202, 1966

12) Tuderman, L.; E. R. KuUtti \& K. I. Kivirikko: An affinity-column procedure using poly(L-proline) for the purification of prolyl hydroxylase. Eur. J. Biochem. 52: 9 16, 1975

13) Sausville, E. A.; J. Peisach \& S. B. Horwitz: A role for ferrous ion and oxygen in the degradation of DNA by bleomycin. Biochem. Biophys. Res. Commun. 73: 814 822, 1976 